\title{
Representation of Women in Amharic Movies
}

\author{
Gebeyehu Ashagare Tiruneh, Seema K.Ladsaria
}

\begin{abstract}
Women are often misrepresented in society all across the globe. They are designated with various roles which can be identified in politics, media, films, and literature. The study aims at exploring women representation in Amharic movies. The Ethiopia film industry seems to be gender biased. One finds men to be better employed as compared to women. Men are in general are given better roles to act where as women are restricted to the roles of maid-servant and subordinates. The aim is to look into the role/jobs given to women in Amharic movies. The study indicates that women in Amharic movies owes less confidence, are economically dependent and are treated as sex toy. Moreover, women are employed in the peripheral jobs in Amharic and mostly are not engaged in production, direction, and cinematography. To improve the women's participation in film industry, some solutions are recommended in the study.
\end{abstract}

Keywords : Representation of women, Amharic movies, films, misrepresentation of women, gender -biased.

\section{INTRODUCTION}

Drama is a basic art to express social and political activities in Ethiopia. It is a form of expression of culture and various dimensions of human life. Theatre and drama are integral part of the Ethiopian society. To quote, Aboneh Ashagre, it has been an "important cultural form in the Ethiopian capital of Addis Ababa for 90 years". It has played an instrumental role in the socio-political upliftment of the country. As such, one finds a range of theatrical activities across Ethiopian region. It addresses issues of politics and art. Nevertheless, the medium of representation such as, radio, television, films and other channel of self-expression often forge the personal identity, self-hood and generalize gender roles.

Women are not given enough space of self-representation. They are underrepresented in political issues, in films, and in media when all is said in done. This study aims to explore women's representation in Amharic movies. Women faced the space of exclusion in the Ethiopian film industry. Until late Twentieth century, "the male-only" casting was popular and women were kept at the fringes of the film industry. Besha Teklemarian says that "the early playwright Yoftahe Negussie and Malaku Baggasaw both wished to train girls on stage but prevailing attitudes about respectable women retaining a purely domesticated role prevented them in succeeding". However, women became freer during the 1960s, both on the social and the personal front, apparently giving women an equivalent balance to men in many parts of life. But, the male dominance of the film business, in the same way as other different ways the world over, is as yet clear in the 21st

Revised Version Manuscript Received on 16 September, 2019.

* Correspondence Author

Gebeyehu Ashagare Tiruneh, PhD Scholar in Literature, Kalinga Institute of Industrial Technology Deemed to be University, Bhubaneswar, Odisha, India

Seema K.Ladsaria, Assistant Professor in the Department of Humanites at Kalinga Institute of Industrial Technology Deemed to be University, Bhubaneswar, Odisha, India. century. Therefore, women seem to have made craved bigger space for themselves accounting a new ideology of participation in the industry.

Representations of women are regularly characterized by how men see women or by how society anticipates that women should look and act. As mentioned above the question of women representation and misrepresentation came to exist. Pitkin classified representation into four: namely, Formalistic representation, symbolic representation, descriptive representation, and substantive representation. Out of the four distinct components of political representation theorized by Pitkin (1967), symbolic representation has since quite a while ago stayed ignored in the literature. Various researchers in the fields of gender, yet in addition ethnic and racial examinations have contemplated the marvel of descriptive representation, and all the more as of late likewise of substantive representation. Pitkin's work has been an imperative touchstone in this, as Celis and Mazur (2012) underline in first experience with a progression of Critical Perspectives on Gender and Politics.

The job of a woman in a film quite often spins around her physical fascination and the mating diversions she plays with the male characters. Then again, a man isn't demonstrated absolutely in connection to the female characters, however in a wide variety of jobs battling against nature (The Old man and the Sea; Moby-Dick; 2001: A Space Odyssey), or against militarism (Dr Strangelove; conundrum), or demonstrating his masculinity on the range any (John Weayne Western).

Women give inconvenience or sexual intermissions to the male characters or are absent by any stretch of the imagination. In spite of when a lady is a focal character she is, for the most part, appeared as confounded, or powerless and in peril, or uninvolved, or as absolutely sexual being . From the above statements, we can infer that women are characterized as they are incapable of doing things; they are a symbol of weakness in a work of art. However, misrepresentation of women in films is a world phenomenon, especially, in Africa, the area needs investigation and many researchers have conducted on women representation in films and politics, but in Ethiopia context it is not investigated properly.

\section{LITERATURE REVIEW}

\subsection{Feminist theories of cinematic representation}

Feminist theory is incorporated because this study looks at representation of women. The main project of feminist film theory is no doubt shared by all within the field of cinema studies: Identify those conditions within the film medium that has fostered and continue to maintain an unjust position for women in society. ${ }^{1}$ Christine Gledhill, for instance, argues that women's film theories may get away "the catch of 
viewing films as reflections, dedicated or twisted, of society."

However, women were declining and misrepresenting in Ethiopian cinema, during 1970 's, they were played a great role in terms of involving the cinema or the theater. Regarding to this, Aboneh added, the most explicit factor that has added to the strengthening of women in the advancement of Ethiopian performance center has without a doubt been the foundation of the Theater Arts Department at Addis Ababa University12 in 1978. So from Aboneh's, one can understand that the opening of Theater and arts department was a springboard for Ethiopian cinema and Art.

Since that time more than 100 young women have graduated with either degrees or recognition in Theater Arts, and women have possessed the capacity to have their spot in all parts of expert theater-production. Some especially striking names incorporate Gifty Abassiya, Marta Sileshy, Azeb Kebede, and Menbere Tadesse who have gone up against official administrative positions in the general population theaters and even ascended to appointee minstrel position in the Ministry of Culture. The creation of Semintu Setoch (The Eight Women) at The National Theater by Azeb Worku in 2007 is likewise special in Ethiopian theater history in that, dissimilar to the 1940s male-ruled theater convention, all characters in the play were women and the stage was absolutely under the control of female entertainers (Ashagre). From Ashagre, one can understand that in 1940's the industry was dominated by men, but in 2007 the narrative changed and the industry were driven by the women.

Finally, the phenomenological theory of true to life representation empowers an investigator of critical parts of film understanding and also issues in the connection between film and society. The female voice in realistic representation is perceived as a property of females as females, that is, female as they are in themselves. Different theorized elements and basic exercises of temporary film theory have been appealed to the method of representation ${ }^{2}$.

From the above anyone can understand that women perceived as object and they were depicted as a servant for men in films, literature and a work of art in general. There for this study aimed to study representation of women in Amharic movies.

\section{METHODOLOGY}

\subsection{The sampling Technique}

At present, there are a lot of directors and producers who are making films in Ethiopia. By using simple random sampling technique both producer and the director are being selected to verify the authenticity of the data. The rationale behind this is the director and the producers are assumed to be rich source of data and also they are engaged in overall activity of the film industry. Therefore, it seems they are aware of things that happen in the industry. Therefore, they considered as one important source of data. Sampling and data collection processes are critical to determining the quality of a study and the findings. ${ }^{3}$

\subsection{Data collection Instruments}

The study employed questionnaire and interview as a research tool.

\subsection{Questionnaire}

Questionnaires are a very convenient way of collecting useful comparable data from a large number of individuals. Accordingly, Close ended questionnaire was conducted with film makers.

\subsection{Interview}

Interviews are is an effective system of knowing one's feeling, mentality, thought, insight, capacity, and depth of knowledge. Thus, the study employed structured interview.

\section{ANALYSIS AND INTERPRETATIONS OF DATA RESULTS OF FILM MAKERS' INTERVIEW AND QUESTIONNAIRE}

The purpose of this study is to investigate women's representation in Ethiopian Amharic movies. To this end, a total of 120 of questionnaires were distributed for film makers. The returned questionnaires were 112 (93\%). The data were analyzed in terms of the frequency, percentage, Mean scores and Standard Deviation. Item scores for each category were arranged under five rating scales. The range of rating scales was strongly disagree $=1$, disagree $=2$, neutral $=$ 3 , agree $=4$ and strongly agree $=5$. For purpose of analysis, the above 5 rank responses of questionnaire were grouped and labeled into three categories i.e. Disagree $\leq 2.50$, Neutral= 2.51-3.5 and agree $\geq 3.41$. Finally, data obtained from open ended items of questionnaire and interview were and analyzed qualitatively and quantitatively to substantiate the data.

\subsection{The Demographic Characteristics of Respondents}

Understanding about overview of respondents demographic characteristics plays a vital for further analysis of responses. Hence, attempt was made to describe background of respondents which is directly or indirectly related to objectives of the study. Accordingly, the demographic characteristics of respondents' sex, age, educational qualification and religion were analyzed and discussed in terms of frequencies and percentage as follows: 
Table 1: The Demographic Characteristics of the Sample Film Makers

\begin{tabular}{llrr}
\hline Variables & Categories & F & Percent \\
\hline Age of the respondents & $18-28$ years & 10 & $8.9 \%$ \\
& $29-30$ years & 14 & $12.5 \%$ \\
& $40-50$ years & 84 & $75 \%$ \\
& 51 years and above & 4 & $3.6 \%$ \\
\hline Sex of the respondents & Female & 3 & $2.7 \%$ \\
& Male & 109 & $97.3 \%$ \\
\hline Educational status & Certificate & 101 & $90.2 \%$ \\
& Diploma & 4 & $3.6 \%$ \\
& First Degree & 5 & $4.5 \%$ \\
& Masters and Above & 2 & $1.8 \%$ \\
\hline Religion & Christian & 74 & $66.1 \%$ \\
& Muslim & 37 & $33.0 \%$ \\
& Other & 1 & $.9 \%$ \\
\hline
\end{tabular}

As the demographic information depicted, that out of the 112 total sample respondents, majorities 109 (97.3\%) were men and, only $3(2.7 \%)$ were women. Thus, it seems that the number of women's' participation in the industry is much lower compared to men. So it needs further investigation why number of female makers' is reducing. Of course numbers of females are less in developed industries also. For example, in Hollywood in the main 100 movies of 2017: Females contained $24 \%$ of heroes $63 \%$ of female characters had an identifiable activity or occupation (contrasted with $78 \%$ of male characters) $55 \%$ of female characters were found in their work setting, really working (versus $69 \%$ of males).

Concerning the educational background of respondents, majority $101(90.2 \%)$ were certificate holders and above label, while $2(1.8 \%)$ of respondents were MA holders, 4
$(3.6 \%)$ of were diploma holder and $5(4.5 \%)$ were degree (BA/BSc) holders. Thus, it seems majority of film makers are self-thought. From the data one can understand that most Ethiopian film makers were amateurs. Unless the industry is run by film professionals, it is hard to improve the quality and quantity of the film industry.

Regarding to the religion composition of sample respondents, 74(66.1\%) were Christians, 37(33\%) were Muslims and the rest $(0.95 \%)$ is other. The sample descriptive statistics shows that there is disparity among religion of respondents, here; the study doesn't mean that religion has direct influence on film makers to involve in the area or in the industry. To say so, it needs further investigation.

Table 2: Female Representation in Ethiopian Amharic movies

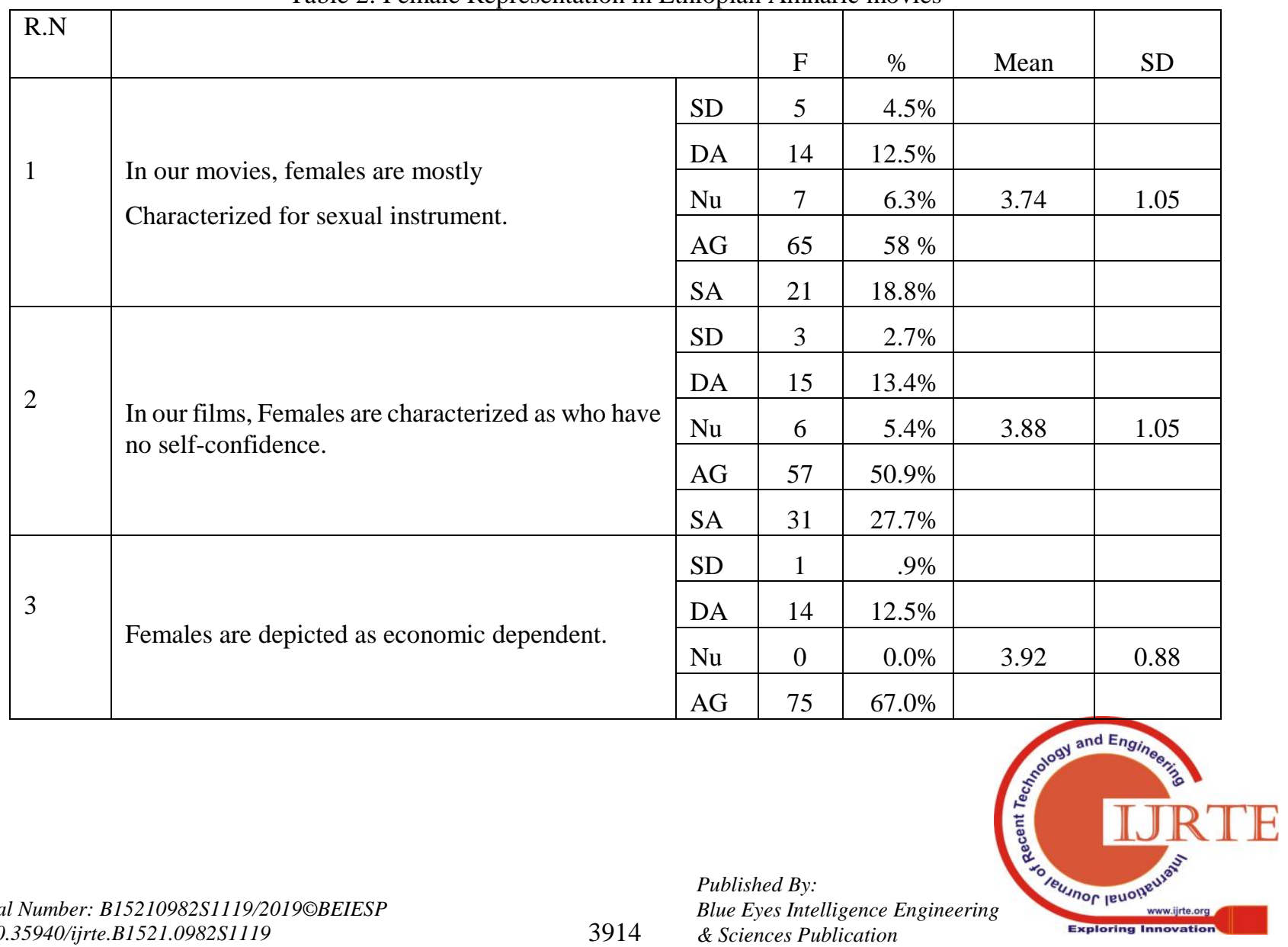




\begin{tabular}{|c|c|c|c|c|c|c|}
\hline & & SA & 22 & $19.6 \%$ & & \\
\hline \multirow{5}{*}{4} & \multirow{5}{*}{ The country has more (enough) female film makers } & SD & 53 & $47.3 \%$ & & \\
\hline & & DA & 54 & $48.2 \%$ & & \\
\hline & & $\mathrm{Nu}$ & 2 & $1.8 \%$ & 1.60 & 0.66 \\
\hline & & $\mathrm{AG}$ & 3 & $2.7 \%$ & & \\
\hline & & SA & 0 & $0.0 \%$ & & \\
\hline & Summary & & & & 3.28 & 0.91 \\
\hline
\end{tabular}

Regarding to item 1 table 2, majority 86 (76.8\%) the sample respondents believed that majority of females in the movies characterized for sexual instrument while 19 (17\%) opposed with the issue and the remaining 7(6.3\%) were neutral. The mean score of the response rate is 3.74 with $\mathrm{SD}=1.05$ also confirms that majority of respondents agreed with the issue. From the above, anyone can understand that women's were characterized as sexual instruments. As many studies indicated, women's are portrayed for sex act in different work of arts.

In item 2 of the same table, respondents asked whether females in Amharic films characterized as lack of self-confidence or not. Accordingly, 88(78.6\%) of sample respondents agreed that female in majority of films characterized as lack of self-confidence, while $18(16.1 \%)$ disagreed with the issue and the reaming $(5.4 \%)$ responded as neutral. The mean score, 3.88 with $\mathrm{SD}=1.05$ also confirms that majority of respondents perceived as most of the time female in the majority of films characterized as lack of self-confidence. However, majority respondents believed that and women's in Amharic films depicted as have no confidence, there are many studies which show women's are confident enough. From this we can understand that because of social effect women are considered unfit.

Concerning item 3 of the same table, respondents asked whether majority films reflects on female as economic dependent on men or not. Accordingly, 97(87.6\%) respondents perceived that majority films depict females as economic dependent whereas $15(13.4 \%)$ oppose with the issue. The mean score 3.92 with $\mathrm{SD}=0.88$ also confirms that majority of Ethiopians' films characterizes females as economic dependent.

Studies have shown that a woman's financial reliance is one of the key pointers of her status in the society eye, characterizing the level of her individual opportunity in public and private life. Especially, in the developing country women's considered dependent. Balabanova, addressed it in his study as follow:

The majority of developing country were monetarily rely upon their men and his financial reliance impact their basic leadership control. Mostly their husband took the decision in their family. From Balabanova study, one can infer that because of social factor woman's are characterized as dependent in movies or real life.

With regard to item 4 of the above table, the sample respondents were asked about does Ethiopia have more (enough) female film makers or not. Accordingly, 107 (95.5) disagreed, on the other hand 3 (2.7) respondents were agreed with the notion, and the remaining 2 (1.8) were marked as neutral. The mean and standard deviation (Mean $=1.60$, $\mathrm{SD}=0.66$ ) indicated that the Ethiopian film industry is dominated by men. Of course reports and studies sown that the world film industry is dominated by men. In Hollywood, from the best 250 movies of 2017,88 percent had no female chiefs, as per the latest "Celluloid Ceiling" report from San Diego State University. Furthermore, 83 percent of the movies had no female writers, and 96 percent had no female cinematographers. As indicated by before forms of the review, in excess of 90 percent of significant studio films have no female assistances on set, including gaffers, key grasps, or supervising sound editors'.

The summary result (Mean=3.28; $\mathrm{SD}=0.91)$ indicated that as the majority of the respondent believed women's are characterized negatively in Amharic movies. It is common that women's are distorted in TV and film. Frequently the female characters work just to serve the male lead or are gender-stereotyped only there for their looks.

As mentioned the methodology part, this study was highly quantitative, but to support the quantitative data, open ended interview were conducted. Four film makers were interviewed. Accordingly, the following discussions are on the results of these qualitative data:

\section{RESULTS OF FILM MAKERS' INTERVIEW}

\subsection{Respondent 01}

Respondent 01 has been working as a film maker since 2000. He made seven films. Among his vast making experience, he was asked about how women's are represented in Amharic movies. His words are as follow:

Women's jobs in film are more changed and various than they used to be, however regardless they are compelled to specific generalizations and talk less regularly than their male partners. So the issue is by all accounts more jumbled than simply getting women's on-screen. Although when they're there, they're unmistakably likely to be distinguished solely by an individual life job e.g. mother, wife than men. I conducted a survey of a movie how often women had dialogue compared with man, and I found that $90 \%$ of the dialogue spoken by men.

From his words, one can understand that women's were given little room on screen, and characterized incapable of doing things.

\subsubsection{Respondent 02}

Respondent 02 have worked in Ethiopian film industry for thirteen years. She was asked the same question, and she answered as follow:

"Women in films are depicted unreasonably and disgracefully. In the first place, numerous Ethiopian screenwriters are man. They don't comprehend lady and I 
don't think they are committed to." She added that "they write what they see. My comprehension of man is poor and writing a male character is dependably a test to me. However, we should go to European movies. In the event that you watch an extraordinary number of them, you see that ladies' are depicted more with more measurements." From her view one can understand that she seems a feminist, and the respondent looks at the issue in the eyes of feminist point of view.

\subsubsection{Respondent 03}

Respondent o3 also well experienced in Ethiopian film industry. His view when asked women represent in Amharic movie is as follow:

I'm gradually ending up increasingly of a film fan and a film maker, so it truly saddens me not to see women's getting equivalent remaining to men on-screen. There's likewise quite a lot more to this portrayal issue, with the women's, and out of action characters staying particularly an uncommon event. Indeed, even behind the camera, decent variety is incredibly poor. Rome wasn't worked in multi day, beyond any doubt, however unquestionably advancement could be made such a great amount of snappier than it at present is?

From the above anyone can understand that women's are representing wrongly and negatively. But the respondent believed that there is an improvement. The respondent has hope and asks a question that Rome was not build in one day. So, according to the respondent we have to work hard so as improve the situation.

\subsubsection{Respondent 04}

Respondent 04 have been involving in the film industry as an actress, writer and producer, and she reacted as follow:

"The representation of women's is regularly utilized as an offering purpose of the movies. Group of on lookers likes to watch women's on screen in different tune and move schedules, in stereotype pictures, in different wear and the impression of women's on screen change every now and then with changing patterns in the constantly advancing society." From this we can infer that film makers use them for their own purpose only."

Women's are as yet delineated or depicted in the old molds of feminist. Courageous women are westernized, as is everything around them, however, this has brought about transforming a lady into a product that should be made a scene of with the goal that the film can sell well. Women's are spoken to as models, one-dimensional character as little girls, spouses, girl in-law, courtesan, sweetheart, and widow. Such generalizations have no identity characteristics, no substance as far as character and disposition; they just exist in connection to men, to legends on screen. They are there as foil to the male characters to feature their qualities.

From the above view, one can infer that most Ethiopian film makers characterized women's for selling their films by seducing their audiences, and they depicted them as serving men.

\subsubsection{Respondent 05}

The last respondent was respondent 5. He is a film maker and, he produced six films. The respondent had the following words towards the representation of women's in Amharic movies.

As a film maker, I have a chance to observe how women's are depicted in Amharic movies. I think, women's are represented negatively in many Amharic films. We film makers used them to sell or to introduce our films. Most of the time in Our film induestry, beoutiful womens will not come back in the second film. Having introduced themselves in the film induestry, they will marry some one and leave the induestry. I observed this situation in Ethiopian film induestry. I can confidently conclude that women are not given room in the industry.

From the respondents notion, anyone can understand that women are not treated as women rather they are instrumental for the induestry.

\section{DISCUSSIONS}

The outline result $($ Mean $=3.28 ; S D=0.91)$ demonstrated that as most of the respondent trusted ladies' are portrayed adversely in Amharic motion pictures. Usually ladies' are abnormal in TV and film much of the time the female characters work just to serve the male lead or are sex stereotyped.

Men and women perform distinctive jobs and at times these jobs don't remain constant for all people. However, a larger part of individuals lives as per these jobs. Society assigned out classes of social jobs to both male and female people, in a similar way that society sees distinctive genders. These gender jobs can be a limit to two people as they can confine the abilities of what guys and females can do. Gender jobs can really oppress people as they can drive them to be what others need them to be.

From this one can understand that individuals or society creates the stereotype, and women's are represented wrongly. Generally, the study indicated that the larger part agreed that women's are not correctly represented to in movies. They are portrayed as less confidence, economically dependent and sex act.

Finally, to enhance the positive characterization of women's in movies, it is recommended that making more grounded female characters would help work loose the issue and a further include a courageous woman (rather than a saint) and shouldn't include a sentimental relationship. Especially, since Ethiopia is a developing country, the film makers have to characterize females as brave, independent, strong or capable of doing things as man to utilize women's as part of the society to boost them as well as the country.

\section{REFERENCES}

1. Balabanova, E. S. "Women's Economic Dependency: Nature, Causes, and Consequences." Sociological Research 46, no. 2 (April 2007) 5-21. doi:10.2753/SOR1061-0154460201.

2. Casebier, Allan. Film and Phenomenology: Towards a Realist Theory of Cinematic Representation. Cambridge University Press, 1991.

3. Flew, Terry. Understanding Global Media. 2007 edition. Basingstoke England; New York: Palgrave Macmillan, 2007.

4. Marshall, Martin N. "Sampling for Qualitative Research." Family Practice 13, no. 6 (1996): 522-526.

5. Mazur, Amy G., and Season Hoard. "Gendering Comparative Policy Studies: Towards Better Science." In Comparative Policy Studies, edited by Isabelle Engeli and Christine Rothmayr Allison, 205-35. London: Palgrave Macmillan UK, 2014 doi:10.1057/9781137314154_10.

6. "The Role of Women on the Ethiopian Stage: Journal of African Cultural Studies: Vol 24, No 1.” Accessed December 28, 2018. 
Representation of Women in Amharic Movies

https://www.tandfonline.com/doi/abs/10.1080/13696815.2012.67305 5 .

7. Thompson, Derek. "The Brutal Math of Gender Inequality in Hollywood." The Atlantic, January 11, 2018 https://www.theatlantic.com/business/archive/2018/01/the-brutal-mat h-of-gender-inequality-in-hollywood/550232/.

8. Thornham, Sue. Feminist Film Theory: A Reader. NYU Press, 1999.

9. "Women and Hollywood." Accessed November 7, 2018. https://womenandhollywood.com/. 